\title{
Uso de acaricidas em Rhipicephalus (B.) microplus de duas regiões fisiográficas do Rio Grande do Sul
}

\author{
The use of acaricides on Rhipicephalus (B.) microplus from two physiogeographical regions of \\ Rio Grande do Sul
}

\author{
Tânia Regina Bettin dos Santos ${ }^{1,2}$, Nara Amélia da Rosa Farias ${ }^{3}$, Nilton Azevedo Cunha Filho ${ }^{3}$ \& \\ Itabajara da Silva Vaz Junior ${ }^{4}$
}

\begin{abstract}
RESUMO
A preocupação com a seleção de populações de Rhipicephalus (B.) microplus resistentes aos acaricidas é mundial. No Brasil, o aparecimento de resistência não é monitorado de maneira sistemática, o que dificulta o seu controle, pois quanto mais rápido a resistência for detectada, menor é o impacto sobre a produção pecuária. No presente estudo foram analisadas, pelo teste de Drummond, trinta populações de carrapatos de duas regiões fisiográficas do sul do Rio Grande do Sul (Serra do Sudeste e Encosta do Sudeste). Foi realizada uma abordagem epidemiológica com os proprietários ou administradores das fazendas para analisar as diferenças e/ou semelhanças das técnicas de manejo e eficácia dos produtos acaricidas (amitraz, cipermetrina, deltametrina, associação de piretróides sintéticos e organofosforados e associação entre organofosforados) entre as regiões. Observou-se que, em relação à eficácia média dos acaricidas, somente houve diferença $(\mathrm{p}<0,05)$ para a deltametrina, sendo maior na Encosta do Sudeste (54\%) em relação a Serra do Sudeste (37\%). Entretanto, ao analisar as eficácias mínimas entre as duas regiões, observou-se que houve diferença $(\mathrm{p}<0,05)$ para o amitraz de $8 \%$ na Serra do Sudeste e $56 \%$ na Encosta do Sudeste, assim como para cipermetrina, que foi 0\% na Serra do Sudeste e 7\% na Encosta do Sudeste, portanto, as eficácias mínimas foram menores na Serra do Sudeste. No levantamento epidemiológico, a maioria das questões abordadas não apresentou diferença estatística $(p>0,05)$, exceto em relação ao número de aplicações de carrapaticidas ao ano que foi maior na Serra do Sudeste. Devido à grande biodiversidade existente entre várias regiões do Brasil, a detecção da resistência deve ser feita de forma regionalizada, já que regiões fisiográficas próximas e semelhantes apresentaram padrões diferentes de manejo e de eficácia aos acaricidas.
\end{abstract}

Descritores: manejo, acaricidas, epidemiologia, Serra do Sudeste e Encosta do Sudeste.

\section{ABSTRACT}

Substantial worldwide attempt has been focused on control and characterization of acaricide-resistant Rhipicephalus (B.) microplus ticks. In Brazil, it is difficult to obtain reliable estimates of the number of acaricide-resistant cases, since there is the lack of an ample data-collecting infrastructure. In the present study, thirty tick populations from two physiogeographical regions of Rio Grande do Sul (Serra do Sudeste and Encosta do Sudeste) were analyzed by means of the Drummond adult immersion test. An epidemiological study was carried out in order to investigate the differences and/or similarities between the management techniques and the efficacy of acaricidal products (amitraz, cypermethrin, deltamethrin, mixture of synthetic pyrethroid and organophosphorated, and mixture of organophosphorated) in the two regions. Analysis showed that acaricide mean efficacies of the deltamethrin were significantly different $(P<0.05)$ with a higher value in Encosta do Sudeste. However, when the minimal efficacies in the two regions were analyzed, differences for amitraz and cypermethrin were observed, with lower values in Serra do Sudeste $(P<0.05)$. In the epidemiological study, most of the questions did not show statistical differences $(P<0.05)$, except for the number of acaricide applications per year, with a higher value in Serra do Sudeste. The results show that region-level surveys can provide a sensible information base and determine the local requirements and allow the implementation of effective interventions, since priorities can differ markedly even between close regions.

Key words: management, acaricides, epidemiology, Serra do Sudeste and Encosta do Sudeste. 


\section{INTRODUÇÃO}

Atualmente, a preocupação com a seleção de populações de Rhipicephalus (B.) microplus resistentes aos acaricidas é mundial. No Brasil, a resistência não é monitorada de uma maneira sistemática, sendo este um fator que dificulta o seu controle, pois a detecção da resistência de forma rápida e precisa, pode reduzir o seu impacto na produção pecuária [1].

A região sul do Rio Grande do Sul engloba três zonas fisiográficas: Litoral (terrenos baixos, solos arenosos, áreas alagáveis, banhados); Encosta do Sudeste (várzeas utilizadas para o cultivo do arroz, além de resíduos de florestas nativas); e Serra do Sudeste (região de campos, e presença de matas nativas) $[5,7]$.

O clima dessa região é sub-tropical úmido e a temperatura média anual é de $18^{\circ} \mathrm{C}$, com chuvas mais concentradas no inverno e na primavera. A umidade relativa do ar varia entre 75 e $85 \%$ [14].

Os bovinos de raças européias são os mais criados na região, sendo mais suscetíveis ao $R$. microplus do que as raças zebuínas [8].

Nos últimos anos, devido ao aumento do número de populações resistentes aos organofosforados e aos piretróides sintéticos, esses foram substituídos pelas formamidinas $[3,16]$. Em 2002, foi confirmada no Rio Grande do Sul, a resistência em uma população de $R$. microplus denominada Cavalcante, as formamidinas [10].

O presente estudo teve como objetivo avaliar a eficácia de acaricidas com diferentes princípios ativos em duas regiões fisiográficas no sul do Rio Grande do Sul (Serra do Sudeste e Encosta do Sudeste), além de realizar uma abordagem epidemiológica para analisar possíveis falhas de manejo que contribuam para a seleção de populações resistentes.

\section{MATERIAIS E MÉTODOS}

Entre janeiro de 2005 e maio de 2007, foram coletados dados sobre o controle do carrapato, além de fêmeas ingurgitadas em bovinos de corte, de sete municípios, localizados na Encosta do Sudeste (Pedro Osório, Cerrito, Morro Redondo, Capão do Leão e Pelotas) e Serra do Sudeste (Piratini, Canguçu), os quais possuem características fisiográficas semelhantes.

Foram aplicados questionários e coletadas fêmeas ingurgitadas, em quinze propriedades de cada região fisiográfica (Serra do Sudeste e Encosta do Sudeste), totalizando trinta amostras.
Os proprietários foram questionados quanto ao grau de instrução, área total da propriedade, área utilizada para agricultura, presença e freqüência da assistência veterinária, dificuldade no controle do carrapato, número de bovinos da propriedade, raça predominante, compra de lotes de animais no ano, controle de entrada de animais, carrapaticida utilizado, número de aplicações de carrapaticidas por ano, épocas de aplicação, critérios para aplicação, utilização de alternativas para o controle do carrapato, utilização de endectocidas e controle da mosca-doschifres.

As amostras de carrapato foram processadas no Laboratório de Parasitologia do Departamento de Microbiologia e Parasitologia do Instituto de Biologia da Universidade Federal de Pelotas (UFPel) pelo teste de Drummond [2], frente a acaricidas comerciais à base de amitraz, piretróides, associações de piretróides com organofosforados e associação de organofosforados.

O teste de Drummont [2] foi realizado em duplicata, contendo cada placa 10 indivíduos com tamanho e peso similares. Os grupos foram imersos por cinco minutos nos produtos comerciais diluídos e o grupo controle imerso em água. As fêmeas ingurgitadas foram removidas da imersão com o auxílio de tamis de plástico, secas em toalha de papel absorvente, colocadas em placas de Petry e mantidas na estufa a $27^{\circ} \mathrm{C}$ e com umidade relativa (UR) superior a $70 \%$, para avaliação da postura dos ovos e eclodibilidade das larvas. No $15^{\circ}$ dia de incubação foi pesada a massa de ovos aparentemente férteis (coloração marrom claro, brilhantes, agrupados) de cada grupo.

Uma amostra da massa de ovos aparentemente férteis de cada grupo foi incubada a $27^{\circ} \mathrm{C}$ e UR superior a $70 \%$, para a análise da eclodibilidade no $30^{\circ}$ dia. A partir destes dados foi avaliado o índice de eficácia de cada produto comercial, através das seguintes fórmulas segundo Drummond [2]:

\section{$\mathrm{IR}=\underline{\text { Peso da massa de ovos X \% de eclosão X } 20.000}$ Peso das fêmeas ingurgitadas}

I R = Índice Reprodutivo

$$
\mathrm{I} E=\frac{(\mathrm{I} R \text { controle }-\mathrm{I} \text { R tratado }) X 100}{\text { I R controle }}
$$

I $\mathrm{E}=\%$ de eficácia 
Os dados foram analisados pelo programa Epi info 6.0, com o intuito de comparar os resultados das duas regiões estudadas (Serra do Sudeste e Encosta do Sudeste) e estabelecer as semelhanças e/ou diferenças entre esses, em relação à eficácia de carrapaticidas sobre populações de $R$. microplus e as técnicas de manejo utilizadas, que podem contribuir para a seleção de populações resistentes aos acaricidas.

\section{RESULTADOS}

Na Tabela 1, observam-se resultados similares entre as duas regiões estudadas, quanto à sensibilidade das populações de carrapatos a produtos à base de amitraz, cipermetrina, e associações de piretróides sintéticos com organofosforados e entre organofosforados. A eficácia média da deltametrina apresentou diferença estatística entre as regiões $(P<0,05)$, sendo menor na Serra do Sudeste.

Somente a associação de fosforados (Clorfenvifós e DDVP) demonstrou índices de eficácia de $100 \%$. Ao analisar as eficácias mínimas dos acaricidas, observou-se que na região da Serra do Sudeste há um menor índice de eficácia que na região da Encosta do Sudeste. Além das diferenças no desviopadrão, através do Teste Qui-quadrado e/ou Teste Exato de Fischer (Epi info 6.) comparando os mesmos produtos entre as duas regiões; observou-se diferença $(P<0,05)$ para o amitraz e cipermetrina (Tabela 1). Na Serra do Sudeste, foi avaliada uma população de carrapatos sobre a qual a eficácia do amitraz foi de $8 \%$, indicando resistência a esse princípio ativo.
Nas regiões, o modo típico de aplicação de acaricidas é a imersão, sendo utilizado em $67 \%$ das propriedades da Encosta do Sudeste e em $60 \%$ na Serra do Sudeste.

No inquérito epidemiológico realizado com os proprietários, na maioria dos pontos abordados não existiu diferença estatística entre as regiões. $\mathrm{Na}$ Tabela 2 pode ser observado que o grau de instrução dos proprietários é baixo em ambas as regiões.

A assistência veterinária é mais presente na Encosta do Sudeste. As raças bovinas mais criadas nas regiões são cruzas de Bos taurus com Bos indicus. A maioria dos proprietários que compra lote de bovinos faz o controle de entrada dos animais com a utilização de endectocida.

O número de aplicações de carrapaticida por ano tem diferença estatisticamente significativa, sendo maior na região da Serra do Sudeste do que na da Encosta do Sudeste, (Tabela 2).

Na região estudada, $100 \%$ dos produtores estudados não aplicam carrapaticida no inverno (clima subtropical) e a frequiência de produtores que realizam a aplicação de acaricidas somente quando visualizam os carrapatos, é grande em ambas as regiões, sendo de $73 \%$ na Encosta do Sudeste e de 93\% na Serra do sudeste, assim, aplicam os acaricidas nos instares partenóginas e teleóginas. A grande dependência dos químicos, e a pouca utilização de outros métodos para o controle do carrapato, são comuns nas duas regiões. Os endectocitas são utilizados em $100 \%$ das propriedades estudadas.

Tabela 1. Eficácias médias dos acaricidas comerciais sobre Rhipicephalus (B.) microplus, nas regiões da Serra do Sudeste e da Encosta do Sudeste no Rio Grande do Sul, em 30 propriedades amostradas no período de janeiro de 2005 a maio de 2007.

\begin{tabular}{|c|c|c|c|c|c|c|c|c|}
\hline \multirow{3}{*}{$\begin{array}{l}\text { Produtos } \\
\text { Comerciais }\end{array}$} & \multicolumn{8}{|c|}{ Eficácia \% } \\
\hline & \multicolumn{4}{|c|}{ Serra do Sudeste } & \multicolumn{4}{|c|}{ Encosta do Sudeste } \\
\hline & Média & Máxima & Mínima & DP & Média & Máxima & Mínima & DP \\
\hline Amitraz & $94^{\mathrm{A}}$ & 100 & $08^{\mathrm{a}}$ & 23,82 & $94^{\mathrm{A}}$ & 100 & $56^{\mathrm{b}}$ & 13,48 \\
\hline Cipermetrina & $50^{\mathrm{A}}$ & 100 & $08^{\mathrm{a}}$ & 23,20 & $58^{\mathrm{A}}$ & 100 & $07^{\mathrm{b}}$ & 32,20 \\
\hline Deltametrina & $37^{\mathrm{A}}$ & 79 & $06^{\mathrm{a}}$ & 72,10 & $54^{\mathrm{B}}$ & 100 & $03^{\mathrm{a}}$ & 39,52 \\
\hline $\begin{array}{l}\text { Cipermetrina }+ \\
\text { Clorfenvifós }+ \\
\text { Citronelal }\end{array}$ & $98^{\mathrm{A}}$ & 100 & $90^{\mathrm{a}}$ & 3,95 & $99^{\mathrm{A}}$ & 100 & $93^{\mathrm{a}}$ & 2,11 \\
\hline $\begin{array}{l}\text { Clorfenvifós + } \\
\text { DDVP }\end{array}$ & $100^{\mathrm{A}}$ & 100 & $100^{\mathrm{a}}$ & 0,00 & $100^{\mathrm{A}}$ & 100 & $100^{\mathrm{a}}$ & 0,00 \\
\hline
\end{tabular}

Valores seguidos de letras minúsculas diferentes, nas linhas, apresentam diferença estatística das eficácias mínimas entre as regiões $(P<0,05)$. Valores seguidos de letras maiúsculas diferentes, nas linhas, apresentam diferença das eficácias medias entre regiões $(P<0,05)$ 
Tabela 2. Inquérito epidemiológico realizado entre janeiro de 2005 a maio de 2007 com os proprietários das fazendas, comparando freqüências(\%) na região da Encosta do Sudeste com da Serra do Sudeste, no Rio Grande do Sul.

\begin{tabular}{|c|c|c|c|c|c|}
\hline \multirow{2}{*}{$\begin{array}{c}\text { Informação } \\
\text { Grau de Instrução }\end{array}$} & \multicolumn{2}{|c|}{ Encosta do Sudeste } & \multicolumn{2}{|c|}{ Serra do Sudeste } & \multirow{2}{*}{$\frac{\mathbf{p}}{0,45}$} \\
\hline & $\begin{array}{l}\text { Analfabeto a } 1^{\circ} \text { grau } \\
67\end{array}$ & $\begin{array}{l}\text { A partir do } 2^{\circ} \text { grau } \\
33\end{array}$ & $\begin{array}{l}\text { Analfabeto a } 1^{\circ} \text { grau } \\
53\end{array}$ & $\begin{array}{l}\text { A partir de } 2^{\circ} \text { grau } \\
47\end{array}$ & \\
\hline \multirow[t]{2}{*}{ Assitência Veterinária } & $\begin{array}{c}\text { Sim } \\
93\end{array}$ & $\begin{array}{l}\text { Não } \\
7\end{array}$ & $\begin{array}{c}\operatorname{Sim} \\
53\end{array}$ & $\begin{array}{l}\text { Não } \\
47\end{array}$ & $0,01^{*}$ \\
\hline & $\begin{array}{c}\text { Periódica } \\
73 \\
\end{array}$ & $\begin{array}{c}\text { Se necessária } \\
27 \\
\end{array}$ & $\begin{array}{c}\text { Periódica } \\
47 \\
\end{array}$ & $\begin{array}{c}\text { Se necessária } \\
53 \\
\end{array}$ & 0,13 \\
\hline $\begin{array}{l}\text { Dificuldade no controle } \\
\text { do carrapato }\end{array}$ & $\begin{array}{l}\text { Sim } \\
27\end{array}$ & $\begin{array}{c}\text { Não } \\
73\end{array}$ & $\begin{array}{c}\text { Sim } \\
40 \\
\end{array}$ & $\begin{array}{c}\text { Não } \\
60 \\
\end{array}$ & 0,43 \\
\hline Raça & $\begin{array}{c}\text { Européia } \\
33\end{array}$ & $\begin{array}{l}\text { Cruza Indiana } \\
67\end{array}$ & $\begin{array}{c}\text { Européia } \\
40\end{array}$ & $\begin{array}{l}\text { Cruza Indiana } \\
60\end{array}$ & 0,50 \\
\hline $\begin{array}{l}\text { Número de Aplicação de } \\
\text { Carrapaticida ao ano }\end{array}$ & $\begin{array}{r}\leq 4 \\
53 \\
\end{array}$ & $\begin{array}{r}>4 \\
47 \\
\end{array}$ & $\begin{array}{r}\leq 4 \\
20 \\
\end{array}$ & $\begin{array}{c}>4 \\
80 \\
\end{array}$ & $0,05^{\#}$ \\
\hline $\begin{array}{c}\text { Critério para Aplicação } \\
\text { de carrapaticida }\end{array}$ & $\begin{array}{c}\text { Visualizaçãoda teleógina } \\
73 \\
\end{array}$ & $\begin{array}{l}\text { Prevenção de infestação } \\
27\end{array}$ & $\begin{array}{l}\text { Visualização da teleógina } \\
93 \\
\end{array}$ & $\begin{array}{c}\text { Prevenção de infestação } \\
7\end{array}$ & 0,16 \\
\hline $\begin{array}{l}\text { Usa alternativa para } \\
\text { o controle do carrapato }\end{array}$ & $\begin{array}{c}\text { Sim } \\
27\end{array}$ & $\begin{array}{c}\text { Não } \\
73\end{array}$ & $\begin{array}{c}\text { Sim } \\
33\end{array}$ & $\begin{array}{c}\text { Não } \\
67\end{array}$ & 0,50 \\
\hline Usa Endectocida & $\begin{array}{l}\text { Sim } \\
100 \\
\end{array}$ & $\begin{array}{c}\text { Não } \\
0 \\
\end{array}$ & $\begin{array}{r}\text { Sim } \\
100 \\
\end{array}$ & $\begin{array}{c}\text { Não } \\
0\end{array}$ & -- \\
\hline $\begin{array}{c}\text { Controle da } \\
\text { mosca-dos-chifres }\end{array}$ & $\begin{array}{c}\text { Sim } \\
47\end{array}$ & $\begin{array}{c}\text { Não } \\
53\end{array}$ & $\begin{array}{c}\text { Sim } \\
60 \\
\end{array}$ & $\begin{array}{c}\text { Não } \\
40\end{array}$ & 0,71 \\
\hline
\end{tabular}

* Diferença estatística significativa $(\mathrm{p}<0,05)$ pelo Teste Exato de Fischer

\# Diferença estatística aparente $(\mathrm{p}=0,05)$ pelo Teste de Qui-quadrado

- Não foi possível o cálculo, utilizado por $100 \%$ dos proprietários

\section{DISCUSSÃO}

As eficácias médias (Tabela 1) dos produtos à base de piretróides foram similares aos verificados em vários estados brasileiros, que relataram eficácias médias baixas aos piretróides, indicando populações resistentes $[3,4,6,9,15]$.

Nas duas regiões estudadas, a base química mais utilizada é o amitraz, mesmo resultado foi obtido por outros autores em estudos realizados no Rio Grande do Sul $[3,16]$.

As associações entre piretróides e organofosforados, assim como entre os organofosforados, apresentaram eficácia média superior aos produtos não associados, em ambas as regiões fisiográficas. Entretanto, cabe salientar que muitas associações não são recomendadas para banheiro de imersão, pois são tóxicas e, além disso, têm mecanismos de ação e período residual distintos, o que pode comprometer a vida útil dessas bases químicas [12].

O modo de aplicação de acaricidas mais utilizado é a imersão, tanto na região da Encosta do Sudeste quanto na da Serra do Sudeste, sendo que dados similares já haviam sido obtidos no Rio Grande do Sul [3], diferentemente de outras regiões do país, onde não se utiliza o método de imersão [13].
No inquérito epidemiológico, pode ser observado que o grau de instrução dos proprietários é baixo em ambas as regiões, similar ao estudo realizado em Minas Gerais [13]. As propriedades amostradas da Encosta do Sudeste possuem um maior índice de assistência veterinária, indicando que os proprietários desta região têm um maior acesso a informações sobre o controle do carrapato. Atualmente, as raças bovinas mais criadas nas regiões são cruzas de Bos taurus com Bos indicus, diferente do observado em estudos anteriores [8].

O número de aplicações de carrapaticida por ano foi maior na região da Serra do Sudeste do que na da Encosta do Sudeste, o que deve ser ressaltado, pois quanto maior o número de aplicação carrapaticida, mais rápida a seleção de populações resistentes $[11,17]$. Apesar da população estudada não demonstrar diferença estatística significativa quanto à área da propriedade que é utilizada para agricultura, é possível que essa diferença ocorra, porque na região da Encosta do Sudeste há várzeas utilizadas para o plantio de arroz e, assim, o consórcio da agricultura com a pecuária ocorre em áreas maiores do que na região da Serra do Sudeste. 
Além disso, deve ser considerado que, na região estudada, $100 \%$ dos produtores amostrados não aplicam carrapaticida no inverno (clima subtropical). Assim, uma freqüência maior que quatro banhos por ano, constatada na região da Serra do Sudeste, somada à grande comercialização de gado existente na região, podem contribuir fortemente para disseminação de populações resistentes aos acaricidas.

A maioria dos produtores amostrados em ambas as regiões, realiza a aplicação de acaricidas somente quando visualiza os carrapatos, assim, aplicam os acaricidas em partenóginas e teleóginas, o que estrategicamente é desaconselhado, pois o melhor controle é obtido quando a aplicação ocorre na fase de larva [8]. Os endectocitas são utilizados em 100\% das propriedades amostradas, fato que merece análise mais detalhada, pois o uso de programas de controle com Lactonas Macrociclicas (endectocidas) é um fator de risco para a seleção de populações de $R$. microplus resistentes [17].

\section{CONCLUSÕES}

Entre as populações de $R$. microplus estudadas, especialmente na região da Serra do Sudeste, existem algumas que apresentam baixos índices de eficácia mínima, para amitraz (8\%), cipermetrina (0\%) e deltametrina (6\%), sugerindo, portanto, populações resistentes a esses princípios ativos.

As eficácias médias observadas, na região da Encosta do Sudeste e da Serra do Sudeste, para produtos comercias onde há associação de organofosforados com piretróides sintéticos e entre organofosforados, foi superior a $95 \%$, portanto, dentro dos índices recomendados pelo Ministério da Agricultura e Abastecimento, até mesmo para o registro de uma base química.

Além dos índices de eficácia observados, a abordagem epidemiológica demonstrou a presença de um número maior de fatores para seleção de populações resistentes na região da Serra do Sudeste, do que na região da Encosta do Sudeste.

No Rio Grande do Sul (e Brasil), a grande diversidade e biodinâmica existentes exigem uma análise de forma sistemática e regionalizada, já que regiões fisiográficas próximas e semelhantes (Serra e Encosta do Sudeste) apresentaram características diferentes de manejo que influenciam a eficácia dos acaricidas e a pressão seletiva a que estão submetidas as populações de carrapato.

\section{REFERÊNCIAS}

1 Baxter G.D. \& Barker S.C. 1999. Isolation of cDNA an octopamina-like, G-protein coupled receptor from the cattle tick, Boophilus microplus. Insect Biocchemistry and Molecular Biology. 29: 461- 467.

2 Drummond R.O., Ernest S.E., Trevino J.L., Gladney W.J. \& Graham O.H. 1973. Boophilus annulatus and Boophilus microplus. Laboratory tests of insecticides. Journal of Economic Entomology. 66: 130-133.

3 Farias N.A.R. 1999. Situación de la resistência de la garrapata Boophilus microplus em la región sur de Rio Grande Del Sur, Brazil. In: Resumos do IV Seminário Internacional de Parasitologia Animal. (Mérida, México). pp.25-30.

4 Fernandes K.R., Golynski A.A., Oliveira C.E. \& Massard C.L. 2004. Características do controle químico do Boophilus microplus no estado do Rio de Janeiro e a relação com a resistência a carrapaticidas In: Resumos XIII Congresso Brasileiro de Parasitologia Veterinária ( Ouro Preto, Brasil). p.307.

5 Fortes A.B. 1962. Compêndio de Geografia Geral do Rio Grande do Sul. 2.ed. Sulina: Porto Alegre, 235p.

6 Furlong J., Prata M.C., Martins J.R.S., Costa Jr. L.M., Costa J.C.R. \& Verneque R.S. 2004. Diagnóstico “in vitro" da sensibilidade do carrapato Boophilus microplus a acaricidas. In: Resumos do XIII Congresso Brasileiro de Parasitologia Veterinária (Ouro Preto, Brasil). p.305.

7 Gianotti C.A. 1994. A fisionomia do Rio Grande do Sul. 3.ed. Porto Alegre: Ed. da Unisinos, 473p.

8 Gonzales J.C. 2003. O Controle do Carrapato do Boi. 3.ed. Passo Fundo: Ed. da Universidade de Passo Fundo, 128p.

9 Martins J.R., Leite R.C. \& Furlong J. 2003. First evaluation of doramectin against a strain of the cattle tick Boophilus microplus with characteristic of resistance to macrocyclic lactones in the field. In: Summary of the V International Seminar in Animal Parasitology (Mérida, México). pp.12-16.

10 Miller R. J., Martins J. R., Ducomez S., Barré N., Solan A., Coure U. \& George J. 2003. Use of a modified-larval packet test (LPT) to measure amitraz susceptibility in Boophilus microplus in Brazil, New Caledonia, and Uruguay, and comparison of the modified - LPT to a modified-Shaw technique for amitraz testing in B. microplus. In: Summary of the V International Seminar in Animal Parasitology (Merida, México). pp.1-3.

11 Nolan I. 1990. Acaricide resistence in single and multi-host ticks and strategies for control. Parasitologia (Roma, Itália). 32: 145-153. 
12 Pereira J.R. 2006. Eficácia in vitro de formulações comerciais de carrapaticidas em teleóginas de Boophilus microplus coletadas de bovinos leiteiros no Vale do Paraíba, estado de São Paulo. (Rio de janeiro, Brasil) Revista Brasileira de Parasitologia Veterinária. 15: 45-48.

13 Rocha C.M.B.M., Oliveira P.R., Leite L.C., Cardoso D.L., Calic S.B. \& Furlong J. 2006. Percepção dos produtores de leite do município de Passos, MG, sobre o carrapato Boophilus microplus (Acari: Ixodae), 2001. Ciência Rural. 36: 12351242.

14 Rosa M. 1985. Geografia de Pelotas. Pelotas: Editora da UFPel, 333p.

15 Silva M.C.L., Sobrinho R.N., Fontgalland G. \& Linhares C. 2000. Avaliação do clorfenvinfós e da cialotrina sobre o Boophilus microplus, colhidos em bovinos da bacia leiteira da microrregião de Goiânia - Goiás. Ciência Animal Brasileira. 2:143-148.

16 Vargas M.S., Céspedes N. S., Sánchez H. F., Martins J. R. \& Céspedes C.O.C. 2003. Avaliação in vitro de uma cepa de campo de Boophilus microplus (Acari: Ixodidae) resistente à Amitraz. Ciência Rural. 33: 737-742.

17 Vivas R.I.R., Días M.A.A., Arevalo F.R., Sanchez H.F., Santamaría V.M. \& Cruz R.R. 2006 Prevalence and potencial risk factores for organophosphate and pyrethroid resistance in Boophilus microplus ticks on cattle ranches from the State of Yucatan, México. Veterinary Parasitology. 136: 335-342. 